\title{
Process and Value: Summary on Government Response in China
}

\author{
Zhihua Bai ${ }^{1}$ \\ ${ }^{1}$ Doctor Candidate in Public Administration, China University of Political Science and Law, Beijing, China \\ Correspondence: ZhihuaBai, Doctor Candidate in Public Administration, China University of Political Science \\ and Law, Beijing 100088, China. E-mail:arthur2006@163.com
}

Received: March 8, $2015 \quad$ Accepted: March 23, $2015 \quad$ Online Published: April 27, 2015
doi:10.5539/par.v4n1p51
URL: http://dx.doi.org/10.5539/par.v4n1p51

\begin{abstract}
Government response is the process in which an administrative organization owning public authority gives positive and necessary response and reply regarding social problems and civil appeal by all kinds of means based on the public interest. The research perspectives at home in China fall into government response as process and government response as value. According to this logic standard, the former research mainly focuses on the concept and connotation of government response, the response model and type and problems and countermeasures encountered in the response, whereas the latter mainly focuses on the relationship between government responsiveness and responsibility and construction of respondent government.
\end{abstract}

Keywords: government of responsibility, government response, respondent government

\section{Introduction}

There are a lot of theories concerning government response in the development process of foreign public administration. David Osborne and Ted Gaebler ever proposed the concept of "customer-oriented", stating that the government was supposed to offer service for its citizens just as customers. Janet V. Denhardt and Robert B. Denhardt thought that the responsibility of the government should be "to serve instead of operating the rudder". James N. Rosenau emphasized that the government ought to cooperate and coordinate with the society to respond together to administration of social public affairs. All these ideas tally with government response. Research on government response in China started mainly after the annual meeting hosted by the International Association of Schools and Institutes of Administration in Beijing in 2000. The theme of this annual meeting was to "consolidate responsibility, responsiveness and efficiency of government."

It is discovered by a general survey of the current research achievements that, Chinese academicians tend to use such textual expressions as "government response", "government response strength", "government responsiveness" and "respondent government" to initiate their studies. From the disciplinary perspective of research, the above studies include public administration science, political sociology, philosophy and system dynamics science, among which the literature on public administration science is the most. From the perspective of research, currently, domestic research is mainly classified into four types. The first type regards specific social hot spots as the research object, such as, new media, internet public events and network views, etc. The second type regards responsiveness of service-oriented government and government of responsibility as the research object, which involves discussion on responsibility and responsiveness of government. The third type regards the public policy decision-making process as the research object, which studies citizen participation and government decision-making, and its focus is citizen internet participation. The fourth type regards respondent government or responsive government as the research object and attempts to construct a new type of government administrative paradigm. In addition, there are also studies that regard region, local government and county-level government at the specific governmental hierarchy as the research object. For convenience of presenting the research achievements in the past one decade in an intuitive way, this paper is going to embark on a systematic study by regarding the research region as the object. At a macro level, the research perspectives at home in China fall into government response as process and government response as value. According to this logic standard, the former research mainly focuses on the concept and connotation of government response, the response model and type and problems and countermeasures encountered in the response, whereas the latter mainly focuses on the relationship between government responsiveness and responsibility and construction of respondent government.

With regards to the research methodology, this paper adopts literature review. Through a systematic summary of 
the articles that have been published in Chinese core journals in the past one decade, the paper draws the outline of the research context about government response. The literature search resorts to CNKI database with the keywords of "government response", "responsiveness" and "respondent government", etc., and the time span from the year 2005 to the year 2014. On this basis, the author screens to finally ascertain the articles required according to the source of the literature and relevancy of the literature content. In the process of summary, the author applies the method of induction with the logic sequence of the universal law for knowing a thing, and constructs a research framework with the clues of concept, mode, problem and countermeasure from the two aspects of process and value.

\section{Government Response as Process}

\subsection{The Concept and Connotation of Government Response}

According to Grover Starling, response is a behavior that an organization makes rapid response to the request of policy change proposed by the public, or, in other words, the government makes super general response to the request proposed by the public. The government response can also be termed as administrative response. Chinese scholars have slightly different definitions on the concept of government response. The following are some representative ones.

He Zukun (2000) believes "government response is the process of public administration in which the government makes positive and sensitive response and reply to the need of the public and the problems they propose" (He, Zukun, pp.7-8). Qi Gong (2006) defines government response as "the process in which the government makes institutional integration of the difference appeal and expectation of the public citizens based on the principle of maximization of public interest on certain economic and social development condition" (Qi, Gong, pp.109-114). Qi Guanghua (2008) holds the view that modern government response is "the process in which the government and civil servants makes reply and response to the extant and potential needs of the society and the citizens by the means of abstract administrative behavior and concrete administrative behavior" (Qi, Guanghua, pp.115-118). In addition, there are also some scholars, such as, GaoFufeng, who defines the government response by regarding the responsiveness of service-oriented government as the object (Gao, Fufeng, pp.81-84, p.98).

With regards to the connotation of government response, the most representative is Lou Chengwu who interprets government response from the perspective of philosophy and who thinks that the connotation of government response is mainly embodied in four aspects, namely, subjectivity, publicity, responsibility and integration (Lou, Chengwu \& Gu, Aihua, pp.97-100).

It can be found from the above statements, government response as process contains five elements in terms of definition of its concept. Firstly, the subject of response is a government organization, administrative organization or public administrator that owns public power. Secondly, the object of response is the interest appeal of citizens and the society. Thirdly, the attitude of response is supposed to be positive and active instead of being negative and passive. Fourthly, the pattern of response is response, reply and answer by all kinds of means. Fifthly, the aim of response is to meet the need of the public and to realize public interest.

\subsection{The Model and Type of Government Response}

Model is the rule that is detected and abstracted from continuously and repeatedly arising events and is high level generalization and summary that has formed experience in resolving problems. At present, the perspective of research on the model and type of government response mainly contains four aspects.

\subsubsection{The Perspective of Government Governance Paradigm}

From the perspective of transition of public administration paradigm, Wang Wei (2005) classifies government response model into three kinds. The first kind is administrative surveillance-type response, which is established under the dimension of the surveillance relationship between the government and its citizens under the knowledge background of the traditional public administration science. The second kind is market service-type response, which is a kind of model generated under the knowledge background of the new public managerialism with the dominant values of "management effect". The third type is democratic governance-type response (Wang, Wei, pp.56-60, p.64).

Based on the judgment of the government on the relationship between public interest and interest of citizens and on the standard of conversion of the leading role of citizens in the visual field of public administration, You Haijiang (2006) summarizes three kinds of government response models, namely, authority-type response model, management-type response model and quasi-market-type response model (You, Haijiang, pp.104-108). 


\subsubsection{The Perspective of Interaction between Government and Citizens}

Sun Fafeng (2010) classifies government response model into three kinds from the perspective of government function, "statement-response" model, "guidance-response" model, and "rights protection-response" model (Sun, Fafeng, pp.120-123). According to the interaction of the two subjects of net citizens and government in government decision making, Weng Shihong and Gu Limei (2012) conclude the model of government response decision making to China internet participation into four kinds, including the first ostrich model in which the net citizens participate while the government does not give any response, the second cuckoo model in which the popular will is firstly publicized and then the government makes passive response, the third queen bee model in which the government participates actively and the popular will partly participates and the fourth mandarin duck model in which the government takes the lead and the government and the public highly interact (Weng, Shihong $\& \mathrm{Gu}$, Limei, pp.37-41).

\subsubsection{The Perspective of the Attitude of Government Response}

Wu Taisheng (2014) starts from the three dimensions of the object, content and time sequence of government response to interpret government response as the three models of distinctive response, selective response and timeliness response (Wu, Taisheng, pp.127-133). From the perspective of government response attitude, Liu Lirui (2009) refers to typical breaking news on the internet in the past few years, and according to the three standards of relevancy between government policy and popular will, the feeling of the public in government response and initiative of government response, he summarizes response of the government to internet popular will at present as the three types of no response, passive response and active response (Liu, Lirui, pp.22-26).

\subsubsection{The Perspective of Government Response Manner and Content}

According to differences in the hierarchy of government response subject and object, Qi Gong (2006) classifies government response into three types. The first type is response that the country or the government makes after they make judgment on certain economic and social development need and trend. The second type is the internal response within the administrative operation system of the local government. And the third type is the government response to social and public appeal.

From the perspective of the response mode of government to internet public events, Li Fang and Han Zhiming (2014) divide government response into discourse response, behavioral response and institutional response ( $\mathrm{Li}$, Fang \& Han, Zhiming, pp.1-8). From the perspective of the object of government response and the mode of response, Qi Guanghua classifies response into law enforcement response, legislative response and prospective response.

Besides, from the perspective of policy participation, the motive of government response can be classified into instrumental response and purposive response. Government response can be classified into government-oriented response and society-oriented response according to the source of the driving force of response. It can be classified into symbolic response and intuitive response according to the meaning of the response behavior.

\subsection{Problems Existing in Government Response and Countermeasures}

\subsubsection{Problems Existing in Government Response}

\subsubsection{Weak Consciousness of Government Response and Insufficient Initiative in Government Response}

The response consciousness of the government is often absent, which is mainly manifested as backward thinking of the response and weak judgment. The government is not sensitive to the progress of the times, and is especially short of perspectiveness expected in application of new technology into the policy process and political field. In addition, some local governments still operates by strictly following the administrative rules. "Instruction with the leader" and "directive of the superior" are still the major motive of government response. The government consciousness and initiative in responding to public appeal is still not optimistic.

\subsubsection{Incomplete Channel of Government Response}

First of all, the traditional response mode is devoid of the characteristics of network, hierarchy and communication. Thus, when its information dissemination channel is relatively single, it is able to keep guidance and control on the public views. Nevertheless, development of the network technology has greatly reinforced the interaction of information dissemination and exchange and has made the traditional response mode incapable of adapting to the new situation. Then, at present, internet interaction between the local government and the public is not yet quite ideal. Quite a large number of local government responses are still confined to the traditional mode, such as, on-the-spot investigation, media report and petition institution, etc. It turns out that the capacity of resource integration is extremely limited and it is difficult to propel mutual collaboration between government 
sectors and to form joint forces to meet the interest appeal of the public. Finally, the programmed information feedback mechanism of the government has not yet been established. Government response is short of interactivity and it is likely that information losses its authenticity in the process of disseminating within the government system.

\subsubsection{Simple Government Response Means and Inappropriate Response Method}

For the time being, the outbreak of mass disturbance across the entire country has something direct with ineffective local government response. In the process of event advent, inadequate response means and inappropriate response mode and method are likely to arouse further worsening of conflict or event, as a result of which the situation may get out of control. In addition, as the consciousness of responsibility for response is weak, the hasty and extreme response mode of the government in the bud of the mass disturbance often becomes a roll booster of the mass disturbance.

\subsubsection{Inadequate Citizen Participation in Government Response}

In the first place, citizens are not enthusiastic in participation. So far as vote is concerned, the problem of low voting capacity exists, which is specifically manifested as having no idea how to vote, how to vote the deputy to the People's Congress and what is the standard to vote the deputy to the People's Congress. Then, the system of citizen political participation is incomplete. The three major approaches in citizen political participation in public policy in China includes citizen hearing, proposal by deputy to the People's Congress and citizen petitioning. However, all other approaches are under exploration. So far, there still has not been any scientific and rational participation approach. Finally, deficiency of the participation system constrains government response. On the premise that there lacks effective participation system and approach, neither are the public able to effectively express their need, nor the government is likely to pertinently offer public service. This leads to the situation that the government offer service whereas the public are not satisfied in many cases.

What's more, the main problems that the government response is faced up with include poor supervision on response, weak consciousness of the responsibility for response and lack of technical means. Some scholars show clearly through their analysis of internet public events that the government and the officials are faced up with such issues as tension of value, tension of technology, tension of system and tension of capacity at the times of internet.

2.3.2 Countermeasures to Enhance Government Response Strength and Improve Government Response Mechanism

\subsubsection{At the Level of Policy and Legal Regulation}

It is necessary to ascertain the content and all aspects involved in government response in the form of legal regulation. On one hand, what is involved in government response is the scope, style, extent, outcome, expense standard, supervision and rewards and punishment in the service offered by the government to the public should be established in the form of legal regulation. On the other hand, it is the rights and obligations of the service shared by the public, the responsibility undertaken by the public, selection and establishment of the service items required, the specific requirement and appeal to failure in the service items required by the public.

\subsubsection{At the Level of Network and Response Carrier}

In the first place, it is necessary to set up e-government. In order for the government to realize bilateral interaction with the society, it needs to set up and construct e-government, which is supposed to become the primary carrier in modern government administration. The most prominent feature of e-government is that it constructs a virtual government, which is able to stride over obstruction from time, space, sector and governmental hierarchy, realize round-the-clock service and set up an interactive response mechanism between the government and the public (Qi, Liguang \& Fan, Yinli, pp.48-50). In the second place, it is necessary to lay emphasis on network public opinion and public will. The government needs to resort to technical popularization and diversification of public will collection to alleviate the digital divide and sends timely feedback on public opinion appeal through internet. The government also needs to pay attention to guiding interaction between the traditional media and internet public opinions, attach importance to and show respect for internet opinion leadership, and guides the internet behavior of new opinion hierarchy (Ding, Baiyun, Gu, Limei \& Chen, Xiansheng, pp. 38-43). In the third place, it is necessary to set up public interactive short message platform mechanism. Government response tends from unilateralization to multidirection. Considering the interactive relationship between the public and the government, the key is to set up such a benign operation response system as public $\rightarrow$ government response carrier $\rightarrow$ government functional sector (decision-making sector) $\rightarrow$ public. 


\subsubsection{At the Level of Construction of Response Flow}

First, at the stage from the public to government, the government should make commitment of policy response on the basis of reflecting the public need, select democratization to realize policy making with appropriate system of holding and put forward corresponding policy and measures. Secondly, at the stage from government to the public, the government applies suitable policy instrument to put the policy it has made into implementation and accepts assessment from the society and evaluation from the public to make the policy get continuously improved in the process of adjustment responding to the need of the public. Thirdly, the flow of government response is a dynamic cyclic process. In this process, the government should take the initiative in collecting feedback information and rectify deviation and make adjustments in time so as to form the benign cyclic process of "decision-making - implementation - feedback - adjustment".

\subsubsection{At the Level of Civil Servant}

Good government response not only calls for sound response mechanism, but also requires the working staff of the government to possess strong response capacity. Without civil servants with high quality, the government response capacity is unlikely to be enhanced. Within the bureaucracy, different requirements are proposed for capacity of different civil servants. Thus, the key is to enhance the capacity of civil servants at different hierarchies that is matched with their position. As for civil servants at the grass-root level, the service consciousness and capacity of execution is the key. As for civil servants at the middle level, analysis and decision-making as well as team organization capacity is the key. As for civil servants at the high level, strategy design, strategic observation and cultivation of the thinking capacity is the core.

\subsubsection{At the Level of Government Accountability}

First of all, it is necessary to reform the examination and evaluation mechanism of power operation and resolve the issue of inconsistence between rights and liabilities. Government affairs and power operation should be open and transparent. Then, it is necessary to strengthen construction of government of responsibility and enhance the initiative of government response. The government response should be brought effectively into the system of accountability through institutional construction so as to urge government at all levels and relevant officials to proactively confront public opinions, respond to public opinions and guide public opinions. Finally, "specific implementation of administrative system of accountability calls for efforts from multiple parties. The government should take the initiative in exploring feasible path of accountability and compile strict and effective supervision network and mechanism. This will ensure that inner-party supervision, judicial supervision, supervision at the governmental hierarchy, auditing supervision, the People's Congress supervision, the Chinese People's Political Consultative Conference supervision and political group supervision each exert their own efforts and play their own role. Besides, it is more important to focus on supervision outside the system and empower participation of such social supervision subjects as media supervision, network supervision, and intermediary organization supervision. This will form a powerful social supervision atmosphere. It is inevitable that enormous joint forces and synthesized effect of supervision are formed with the matrix network of supervision which has been formed with merger of the double swords both inside and outside the system, the bilateral supervision, horizontal supervision to the side and vertical supervision to the bottom and the mechanism of accountability of the government will be placed into practice effectively ( $\mathrm{Li}$, Weiquan, pp.42-45).

\subsubsection{At the Level of Citizen Participation}

First, it is necessary to broaden and improve institutional expression of interest and integration mechanism to enable concern from all works of the society to be rationally integrated into the public administration mechanism of government and guide the citizens to participate in the national administration in good order. Second, it is necessary to improve the participation approach and channel. Third, it is necessary to strengthen education, enhance the political and cultural quality of citizens, provide the public with training on political participation and impart knowledge and technology in terms of political participation. Fourth, it is necessary to cultivate and develop social intermediary organization.

\section{Government Response as Value}

This sort of research views government response as a kind of property of value. The research field is mainly concentrated on the relationship between responsiveness of the government and responsibility of the government and construction of respondent government which regards government response as the logical starting point.

\subsection{Whether Responsibility of the Government Can Take the Place of Responsiveness}

Relationship between responsiveness of government and responsibility of government is one of the research fields that discuss government response from the perspective of value. 
Professor Zhang Chengfu points out, in a wide sense, responsibility of government means that the government is able to make positive response to the need of the social public and takes positive measures to realize the need and interest of the public in a fair and effective way. In this sense, responsibility of government means the social response of the government. However, "meaning" does not mean that responsibility of the government can take the place of its responsiveness. According to Chen Guoquan (2008), there is internal connection between the three attributes of responsibility, responsiveness and service of the government. Responsibility is the motive of the government, service is the target of the government, whereas responsiveness is the transmission mechanism for the government to realize its target.

With regards to the issue whether responsiveness of government can take the place of the responsibility of government, Liu Zhaoxin (2012) believes there exists logical fallacy in responsiveness of government. It, on one hand, acknowledges the necessity that the government holds public power to resolve social problems, and, on the other hand, negates the subjectivity of public power operation. It is a kind of stimulus - response thinking mode. Thus, it is necessary to replace responsiveness with responsibility, as response is not what is required on the part of government, but responsibility is what has to be undertaken by government. In order to surpass boundedness of the logic of responsiveness, it is necessary to establish the administrative principle of responsibility. He Yongsong (2012) believes there is no fallacy in responsiveness, as responsiveness and responsibility are both high embodiment of government responsibility. Replacement of responsiveness with responsibility goes counter to the fact that "responsiveness and responsibility are mutually based on each other". In the process of public administration, it is not only necessary to pay attention to responsiveness, but also necessary to lay emphasis on responsibility.

Although there exist a lot of disputes, a large number of scholars still believe that responsiveness of government and responsibility of government are both the property of value of the government and the two should not be equal. Response to the public is a due responsibility of the government, whereas responsibility is inherent with the government.

\subsection{Respondent Government and Its Construction}

In the past few years, a large number of scholars have suggested constructing a new type of government governance mode with government response as the logic starting point, namely, respondent government, which is also termed by other scholars as responsive government. The research content at present is mainly concerned with the concept, characteristics and construction approach of the respondent government.

\subsubsection{Definition on the Concept of Respondent Government}

In terms of the definition on the concept, a common sense from the scholars is, first, respondent government is a kind of governance mode, second, its value is to maintain public interest and respond to public need and third, citizen participation and cooperation in governance is its main feature.

Lu Kunjian (2008) holds the view that respondent government is a kind of government and governance mode in which public governance is the idea and the responsibility is to resolve public problems and social problems, which embodies people-oriented, service-orientation, cooperation in governance, response in time and governance pursuant to the law, which has stable, reliable and sustainable development responsiveness and response mechanism and which has the response power required to effectively respond to the society.

Liu Zelun and Liu Xiaoyun (2006) think respondent government is constructed on the basis of positive government administration and participation of citizens and social intermediary organizations in administration. The government listens to the public interest appeal of the society by means of diversified channels and makes positive response through institutional supply and specific administrative behavior. This is aimed to achieve negotiation balance between ordering mechanism of the country and ordering mechanism of the market and realize the target of social public interest. Meanwhile, the government implants a kind of self-rectification into the process of government administration.

\subsubsection{Features of Respondent Government}

The characteristics of respondent government mainly contain the following five aspects. First, there are multiple subjects in respondent government. The government is no longer the unique subject in dealing with public affairs. In terms of the dimensionality of rights, it is no longer top-down, but parallel, multi-dimensional and interactive. Second, respondent government is positive instead of being passive and negative. Third, the respondent government emphasizes participation of government. Fourth, response of the respondent government is a kind of response based on a vision field of globalization. Fifth, the respondent government embodies game playing in the two aspects of governance process and government outcome. The multiple government subjects are under 
constraint of legal and rational game playing rules and conduct a negotiation equilibrium on a fair and orderly game playing platform.

\subsubsection{The Approach to Construction of Respondent Government}

The construction process of respondent government is also a process to enhance the capacity of government response. The scholars have proposed their own suggestions from different perspectives. First, they suggest strengthening institutional construction and establishing administrative disclosing system, democratic decision-making system and administrative responsibility system. Second, it is suggested to improve the response mode and response carrier. To this end, it is necessary to build e-government, facilitate government information disclosure and realize modernization of social management means. Third, it is required to cultivate a civil society. Emergence of social intermediary organization helps to remedy the double whammy of market failure and government failure and improve the management efficiency of public affairs as well as the supply capacity of public service. So far as government is concerned, the power of government is an internal factor, while the power of the society is an external factor and the social power is an indispensable external condition to build a respondent government. So far as the society is concerned, the power of the society is an internal factor, while the power of the government is an external factor and the social power is a determinant condition to construct a respondent government. Fourth, it is suggested to make innovation on the response mode. Li Weiquan (2010) believes only if participation is strengthen, can response be better made. He proposes the three modes in constructing a participatory and respondent government, namely, the democratic decision-making and response mode based on the public agenda, the policy network mode based on interaction between interest and resource and the response mode based on participation of citizens as rights.

\section{Conclusion and Directions for Further Research in the Future}

Currently, there are substantial researches concerning government response, but there also exist a lot of problems, such as, narrow research perspective and lack of depth in analysis, etc. At the same time, there are also some disputes. For instance, there is no unified standard on the definition of the concept of government response. The value property and instrumental property of respondent government are not yet clear. Its relationship with service-oriented government and government of responsibility is also not quite clear.

Specifically speaking, at the level of process, regarding the research method and article structure, most articles use the method of case analysis and have the wording structure of background - case - problem countermeasure. Yet, selection of cases is lacking in representativeness and analysis of cases is lacking in depth, with narrow research perspective. With regards to analysis of problem, there is too much descriptive language, with less analysis and induction, and even less analysis from the perspectives of political system and traditional culture. Some articles offer corresponding countermeasures even after simple description of the problems, without incomplete wording logic. With regards to the research perspective of countermeasure, there is too much similarity on countermeasures offered by the articles, with bad operability. Finally, it is necessary to point out that, from the current research achievements, the scholars have not yet determined the relationships between government response and government management and between government response mechanism and government management mechanism.

At the level of value, firstly, regarding the new paradigm of government governance, no consensus has been reached on whether the concept is "respondent government" or "government of responsiveness". Most of the current research achievements recognize the concept of "respondent government". Then, the theoretical framework of respondent government has not yet been constructed. Although governance is the idea of the new paradigm, the value property and instrumental property of respondent government are still ambiguous, without explanation on the mechanism of interaction between the government and the public. Finally, the relationship between respondent government, service-oriented government and government of responsibility is not quite clear. If respondent government is a new kind of administrative paradigm, then what's its difference from other paradigms, and why it is new. If respondent government is not a new kind of paradigm, then what is the relationship between it and the service-oriented government and the government of responsibility. It needs further explanation on whether this kind of relationship is amendment or supplement.

The directions for future research mainly include the following several aspects. In the first place, differences between government response and the government management and government governance should be studied. As a new kind of administrative paradigm, what kind of technical processing is required to integrate perfectly the governance theory with the extant administrative paradigm. In the second place, from the perspective of the systematic theory, it is necessary to study the influences of the external factors of political system, cultural tradition and social development and the internal factors of government organizational structure, administrative 
institutional reform of the government and administrative paradigm transition of the government on responsiveness of the government. In the third place, the future research should study the relationship between government response and citizen participation and make clear of the mechanism of interaction between the two, so as to determine how to enhance the government response capacity by means of citizen participation and how to enhance the participation capacity of the citizens by means of effective government response. In the fourth place, it is necessary to study the effect of e-government on improving responsiveness or response strength of government. Construction of e-government in China has already begun to take shape. A large majority of local governments have set up their own electronic office system. However, further research is required with regards to whether all the electronic office systems have played their role in improving the response strength of government and with regards to their effect in responding to network politics, network views and network contest. In the fifth place, it is required to break through the research frame of problem-countermeasure, broaden the research extension and perspective of government response and considers government response as an approach to transform government function and enhance the national governance capacity and modernization of government governance.

\section{References}

Ding, B. Y., Gu, L. M., \& Chen, X. S. (2012). Research on Network views and Government Response Mechanism. Journal of Zhejiang Provincial Party School, (5), 38-43.

Gao, F. F. (2009). Response Analysis of Government in Service-oriented Government Construction. Journal of North China Electric Power University (Social Sciences), (6), 81-84, 98.

He, Z. K. (2000). The Focus on Government Response. Chinese Public Administration, (7), 7-8.

Li, F., \& Han, Z. M. (2014). The intensity and Its Analysis of the Government's Response-In the Perspective of the internet Public Incidents. Journal of Northeast Normal University (Philosophy and Social sciences), (1), $1-8$.

Li, W. Q. (2002). Interactive Decision Making: Construction of the Government Decision-making Mechanism. Probe, (3), $42-45$.

Liu, L. R. (2009). Growth of Public Network Views, Political connotations and Government response in China. Journal of Guangdong Institute of Public Administration, (5), 22-26.

Lou, C. W., \& Gu, A. H. (2006). The Philosophical Interpretation of Administrative Response. Chinese Public Administration, (9), 97-100.

Qi, G. (2006). Social Transformation, Social Governance, and Social Response Mechanism Chain. Journal of Southwest China Normal University (Humanities and Social Sciences Edition), (11), 109-114.

Qi, G. H. (2008). Competence Model of Civil Servants Based on Government Response. Chinese Public Administration, (5), 115-118.

Qi, L. G., \& Fan, Y. L. (2009). Institutional analysis on the Lack of Government Response Mechanism. Economic and Social Development, (2), 48-50.

Sun, F. F. (2010). Government Response: The Key to Play Policy Influence of Civil Society in China. Guangxi Social Sciences, (5), 120-123.

Wang, W. (2005). The Transformation of Government Response on connotation and Model. Probe, (1), 56-60, 64.

Weng, S. H., \& Gu, L. M. (2012). The Response Modes of Government Decision-making to Internet Political Participation. Chinese Public Administration, (8), 37-41.

Wu, S. T. (2014). The Action choice of Local government response to public Based on Policy Participation. Guangxi Social Sciences, (1), 127-133.

You, H. J. (2006). The Transformation and practice of Government Response on dominant pattern. Chongqing Social Sciences, (12), 104-108.

\section{Copyrights}

Copyright for this article is retained by the author(s), with first publication rights granted to the journal.

This is an open-access article distributed under the terms and conditions of the Creative Commons Attribution license (http://creativecommons.org/licenses/by/3.0/). 